\title{
Influence of Certain Sterols and 2:4-Dinitrophenol on Phosphate Accumulation and Distribution in Tetrahymena pyriformis
}

\author{
By R. L. CONNER, MELODEE S. KORNACKER* \\ AND ROSELYN GOLDBERG $\dagger$ \\ Department of Biology, Bryn Marw College, Bryn Mawr, \\ Pennsylvania, U.S.A.
}

(Received 23 March 1961)

\begin{abstract}
SUMMARY
Orthophosphate accumulation by Tetrahymena pyriformis $\mathrm{W}$ was enhanced by stigmasterol, $\beta$-sitosterol or cholesterol and depressed by $2: 4$-dinitrophenol (DNP) to an extent determined by the concentration of DNP and hydrogen ion in the suspension medium. The depression of phosphate accumulation by DNP was mitigated by the addition of stigmasterol, the degree of annulment being dependent in part on the stigmasterol concentration. The distribution of accumulated phosphate was not significantly altered by the addition of sterol and/or DNP under the conditions used, indicating that these compounds may influence entry of orthophosphate by affecting a membrane phenomenon.
\end{abstract}

\section{INTRODUCTION}

The interaction of sterols and 2:4-dinitrophenol (DNP), colchicine and several steroids in the growth of Tetrahymena pyriformis has been reported (Conner, 1957; Conner \& Nakatani, 1958; Conner, 1958, 1959 $a, b$ ). The growth inhibitors represent a wide variety of compounds that have been reported to interfere with phosphate metabolism. Colchicine (Lettre, 1951) was reported to inhibit ATPase activity; steroids have been shown to interfere with oxidative phosphorylation and to stimulate 'latent' ATPase activity in mitochondria (Wade \& Jones, 1956a, b), as does 2:4-dinitrophenol (Loomis \& Lipmann, 1948; Hunter, 1951). DNP is believed to lead to a loss of some of the energy which is normally available to cells through oxidative processes; accordingly, energy-dependent growth and maintenance become diminished. The lowering of phosphate accumulation in Tetrahymena in the presence of DNP was reported by Conner, Goldberg \& Kornacker (1961). Van Wagtendonk \& Wulzen (1951) showed that guinea-pigs fed a diet deficient in plant sterols ('anti-stiffness' factor) developed a syndrome most readily explained in terms of a disturbance of phosphate metabolism. These findings, coupled with the DNP inhibition of phosphate accumulation in Tetrahymena, led to a study of the relationship of sterols and DNP to phosphate accumulation and distribution in this ciliated protozoan.

* Present address : Department of Biochemistry, Brandeis University, Waltham, Massachusetts, U.S.A.

$\dagger$ Present address: Department of Microbiology, University of Pennsylvania, Philadelphia, Pennsylvania, U.S.A. 


\section{METHODS}

The organism used was Tetrahymena pyriformis W; it was grown in a proteose peptone medium at $\mathrm{pH} 6.5$ for the phosphate accumulation studies. For the distribution experiments the organism was grown in a modification of the chemically defined medium previously used for growth studies (Conner, 1959b). In the present study the phosphate concentration was decreased by a factor of ten and the Tween 80 was omitted.

Stigmasterol was added to the suspension medium as an aqueous emulsion, prepared by dissolving the sterol in absolute ethanol and injecting the ethanolic solution into distilled water (at about $90^{\circ}$ ) with a fine-tipped pipette. An ethanol blank was prepared at the same time and an equal volume added to all flasks to which the sterol emulsion was not added. The dilutions used gave final concentrations of ethanol in the suspension medium of not greater than $0.05 \%(\mathrm{v} / \mathrm{v})$.

The ciliates were incubated with the sterol emulsion or ethanol blank for $1 \mathrm{hr}$. before the addition of DNP; labelled orthophosphate $\left({ }^{32} \mathrm{P}\right)$ was added $15 \mathrm{~min}$. after the DNP, and the organisms removed from the suspension medium $2 \mathrm{hr}$. after the phosphate addition. The experimental procedures used and the method of calculation were as described by Conner et al. (1961).

\section{RESULTS}

In all experiments accumulation of orthophosphate by Tetrahymena pyriformis $\mathbf{W}$ was augmented by the addition of stigmasterol, lowered by DNP, and the DNP effect was mitigated by the stigmasterol (Figs. 1, 2). The increase in orthophosphate accumulation in the presence of a given concentration of stigmasterol was variable, ranging from 2 to $14 \%$ in a series of sixteen experiments. The ethanolic solution had no effect on phosphate accumulation.

The influence of DNP concentration with regard to orthophosphate accumulation is shown in Figs. 1 and 2 . At $\mathrm{pH} 6.5$ a concentration of $2.5 \times 10^{-5} \mathrm{M}-\mathrm{DNP}$ inhibited approximately $68 \%$ of the phosphate accumulation while at $\mathrm{pH} 7.5$ a DNP concentration of $2 \times 10^{-4} \mathrm{M}$ inhibited to about the same extent. The concentration of undissociated DNP at $\mathrm{pH} 6.5$ is $8.25 \times 10^{-8} \mathrm{M}$ and at $\mathrm{pH} 7.5$ is $6.6 \times 10^{-8} \mathrm{M}$.

The use of a single concentration of DNP and different amounts of stigmasterol resulted in considerable variation in the degree of protection afforded by the stigmasterol, indicating that one or more factors were not adequately controlled in these seven experiments. Figure 3 shows the results of an experiment which most clearly indicated an effect of a sterol concentration gradient. Little difference either in augmentation or in annulment of the DNP inhibition of phosphate accumulation was noted when cholesterol or $\beta$-sitosterol were used in place of stigmasterol.

The results of experiments determining the distribution of the accumulated phosphate are given in Table 1. Within a given experiment, the distribution of radiophosphate in the three fractions in terms of percentages remained constant in the presence of DNP and/or stigmasterol, even though an alteration of total radiophosphate accumulation was brought about by these substances. Experiments were performed in duplicate as a gauge of the reliability of the method used; solutions and animals were taken from the same stocks, and time factors were 
Table 1. Inter-experimental range of percentage accumulation and percentage of radiophosphate recovery in trichloroacetic acid (TCA)-insoluble, TCA-soluble organic and inorganic fractions following treatment of Tetrahymena with $D N P\left(1 \times 10^{-4} \mathrm{M}\right)$ and stigmasterol $\left(1 \times 10^{-5} \mathrm{M}\right)$ at $\mathrm{pH} 7 \cdot 0(8$ experiments $)$

\begin{tabular}{|c|c|c|c|c|c|c|c|c|}
\hline \multirow[b]{3}{*}{ Flask } & & & \multicolumn{6}{|c|}{ Phosphate distribution } \\
\hline & \multicolumn{2}{|c|}{$\begin{array}{c}\text { Accumulation } \\
(\%)\end{array}$} & \multicolumn{2}{|c|}{$\begin{array}{c}\text { TCA-insoluble } \\
(\%)\end{array}$} & \multicolumn{2}{|c|}{$\begin{array}{l}\text { TCA-soluble } \\
\text { organic }(\%)\end{array}$} & \multicolumn{2}{|c|}{$\begin{array}{c}\text { Inorganic } \\
(\%)\end{array}$} \\
\hline & $\begin{array}{c}\text { Mean } \pm \\
\text { s.D.* }\end{array}$ & Range & $\begin{array}{c}\text { Mean } \pm \\
\text { s.D.* }\end{array}$ & Range & $\begin{array}{c}\text { Mean } \pm \\
\text { s.D.* }\end{array}$ & Range & $\begin{array}{c}\text { Mean } \pm \\
\text { s.D.* }\end{array}$ & Range \\
\hline Control & $86 \pm 5$ & $78-90$ & $20 \pm 4$ & $15-28$ & $11 \pm 4$ & $8-13$ & $69 \pm 4$ & $64-76$ \\
\hline $\begin{array}{c}\text { Stigmasterol } \\
\left(1 \times 10^{-5} \mathrm{M}\right)\end{array}$ & $91 \pm 5$ & 82-95 & $22 \pm 5$ & $\mathbf{1 5}-\mathbf{3 0}$ & $11 \pm 4$ & 8-14 & $67 \pm 5$ & $60-75$ \\
\hline $\begin{array}{l}\text { DNP } \\
\left(1 \times 10^{-4} M\right)\end{array}$ & $44 \pm 9$ & $\mathbf{3 1 - 5 3}$ & $15 \pm 8$ & $5-28$ & $17 \pm 4$ & 11-23 & $68 \pm 6$ & $58-77$ \\
\hline $\begin{array}{l}\text { DNP + } \\
\text { stigmasterol }\end{array}$ & $64 \pm 5$ & $56-72$ & $17 \pm 6$ & 12-27 & $15 \pm 3$ & 10-22 & $68 \pm 3$ & $63-72$ \\
\hline
\end{tabular}

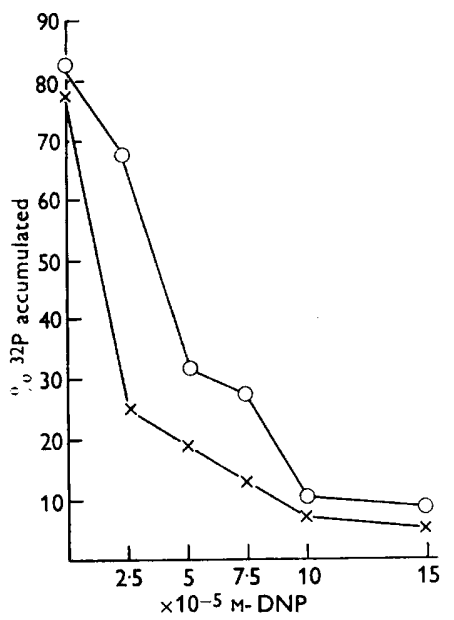

Fig. 1

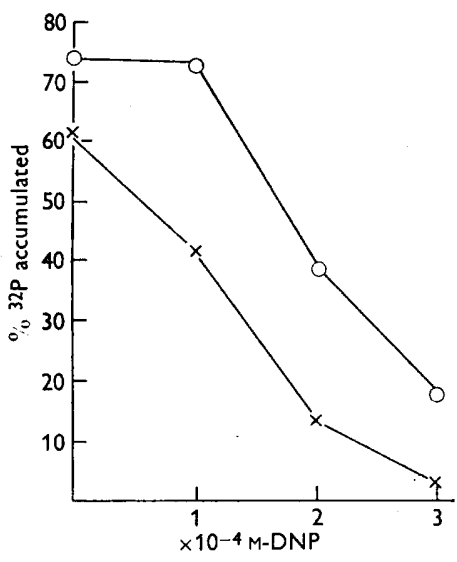

Fig. 2

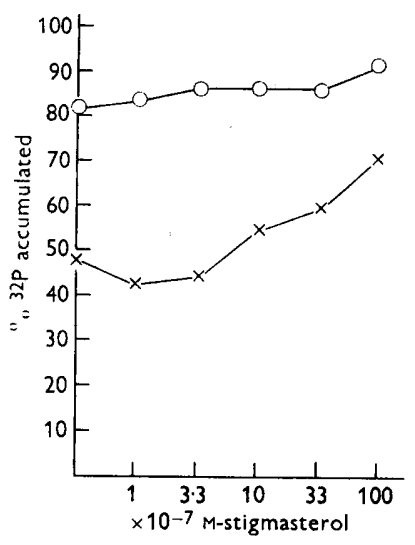

Fig. 8

Fig. 1. The influence of DNP and stigmasterol on phosphate accumulation in Tetrahymena. One ml. of organism suspension at an optical density of 0.5 as determined by a Lumetron colorimeter using a $650 \mu$ filter was added in a final volume of $10 \mathrm{ml}$. suspension at $\mathrm{pH}$ 6.5. Suspension medium containing DNP $(x-\infty)$. Suspension medium containing DNP and $1 \times 10^{-5} \mathrm{M}$-stigmasterol $(\mathrm{O}-\mathrm{O})$.

Fig. 2. The influence of DNP and stigmasterol on phosphate accumulation in Tetrahymena. Two ml. of organism suspension at optical density of 0.5 in a final volume of $10 \mathrm{ml}$. Suspension medium at $\mathrm{pH} \mathrm{7.5}$; with DNP $(\times-\times)$, with DNP and $1 \times 10^{-5} \mathrm{M}$ stigmasterol $(\mathrm{O}-\mathrm{O})$.

Fig. 3. The influence of stigmasterol and $1 \times 10^{-4} \mathrm{M}-\mathrm{DNP}$ on phosphate accumulation in Tetrahymena. Two ml. organism suspension at optical density 0.5 in a final volume of $10 \mathrm{ml}$. suspension medium at $\mathrm{pH} 7 \cdot 5$. Stigmasterol $\left(\mathrm{O}^{-} \mathrm{O}\right)$; stigmasterol and $1 \times 10^{-4}$ M-DNP $(x-x)$. 
Table 2. Determination of accumulation and distribution of radiophosphate in Tetrahymena in the presence of DNP $\left(1 \times 10^{-4} \mathrm{M}\right)$ and/or stigmasterol $\left(1 \times 10^{-5} \mathrm{M}\right)$ at $\mathrm{pH} 7 \cdot 0$, in duplicate experiments

\begin{tabular}{|c|c|c|c|c|c|}
\hline $\begin{array}{l}\text { Exp. } \\
\text { no. }\end{array}$ & $\begin{array}{c}\text { Flask } \\
\text { contents }\end{array}$ & $\begin{array}{l}\% \text { removed } \\
\text { from medium }\end{array}$ & $\begin{array}{c}\text { TCA } \\
\text { insoluble* }\end{array}$ & $\begin{array}{c}\text { TCA } \\
\text { soluble* }\end{array}$ & Inorganic* \\
\hline $1 a$ & $\begin{array}{l}\text { Control } \\
\text { Stigmasterol } \\
\text { DNP } \\
\text { DNP + stigmasterol }\end{array}$ & $\begin{array}{l}87 \pm 1 \cdot 0 \\
95 \pm 1 \cdot 0 \\
42 \pm 2 \cdot 0 \\
66 \pm 1 \cdot 5\end{array}$ & $\begin{array}{l}22 \pm 1 \cdot 0 \\
30 \pm 1 \cdot 0 \\
22 \pm 2 \cdot 5 \\
23 \pm 2 \cdot 0\end{array}$ & $\begin{array}{r}10 \pm 1 \cdot 0 \\
8 \pm 1 \cdot 0 \\
11 \pm 3 \cdot 0 \\
11 \pm 2 \cdot 0\end{array}$ & $\begin{array}{l}68 \pm 1 \cdot 0 \\
62 \pm 1 \cdot 0 \\
66 \pm 2 \cdot 0 \\
65 \pm 2 \cdot 0\end{array}$ \\
\hline $1 b$ & $\begin{array}{l}\text { Control } \\
\text { Stigmasterol } \\
\text { DNP } \\
\text { DNP + stigmasterol }\end{array}$ & $\begin{array}{l}89 \pm 1 \cdot 0 \\
95 \pm 1 \cdot 5 \\
48 \pm 1 \cdot 0 \\
72 \pm 1 \cdot 5\end{array}$ & $\begin{array}{l}28 \pm 1 \cdot 5 \\
29 \pm 1 \cdot 0 \\
28 \pm 2 \cdot 0 \\
27 \pm 2 \cdot 5\end{array}$ & $\begin{array}{r}8 \pm 1 \cdot 5 \\
12 \pm 1 \cdot 0 \\
14 \pm 2 \cdot 0 \\
10 \pm 3 \cdot 0\end{array}$ & $\begin{array}{l}64 \pm 1 \cdot 5 \\
59 \pm 1 \cdot 5 \\
58 \pm 2 \cdot 5 \\
63 \pm 3 \cdot 0\end{array}$ \\
\hline $4 a$ & $\begin{array}{l}\text { Control } \\
\text { Stigmasterol } \\
\text { DNP } \\
\text { DNP + stigmasterol }\end{array}$ & $\begin{array}{l}79 \pm 1 \cdot 5 \\
84 \pm 1 \cdot 5 \\
32 \pm 1 \cdot 5 \\
60 \pm 1 \cdot 5\end{array}$ & $\begin{array}{l}19 \pm 1 \cdot 5 \\
23 \pm 1 \cdot 0 \\
16 \pm 3 \cdot 0 \\
15 \pm 1 \cdot 5\end{array}$ & $\begin{array}{l}12 \pm 1 \cdot 0 \\
13 \pm 1 \cdot 0 \\
14 \pm 2 \cdot 0 \\
16 \pm 1 \cdot 0\end{array}$ & 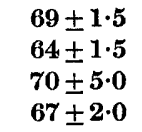 \\
\hline $4 b$ & $\begin{array}{l}\text { Control } \\
\text { Stigmasterol } \\
\text { DNP } \\
\text { DNP + stigmasterol }\end{array}$ & $\begin{array}{l}78 \pm 2 \cdot 0 \\
82 \pm 2 \cdot 0 \\
31 \pm 2 \cdot 0 \\
56 \pm 2 \cdot 0\end{array}$ & $\begin{array}{l}19 \pm 1 \cdot 5 \\
19 \pm 1 \cdot 5 \\
20 \pm 3 \cdot 5 \\
17 \pm 2 \cdot 0\end{array}$ & $\begin{array}{l}14 \pm 1 \cdot 0 \\
12 \pm 1 \cdot 0 \\
16 \pm 5 \cdot 0 \\
16 \pm 2 \cdot 0\end{array}$ & $\begin{array}{l}67 \pm 1 \cdot 5 \\
69 \pm 1 \cdot 5 \\
63 \pm 5 \cdot 0 \\
67 \pm 3 \cdot 0\end{array}$ \\
\hline
\end{tabular}

* Given as percentage of phosphate accumulated.

controlled as closely as possible. Representative duplicate experiments (Table 2) revealed an uncertainty up to $6 \%$ in phosphate accumulation and $8 \%$ in distribution (see also Kamen \& Spiegelman, 1948).

\section{DISCUSSION}

In light of available information about phosphate metabolism it is reasonable to propose the following pathway in Tetrahymena pyriformis $\mathbf{W}$ :

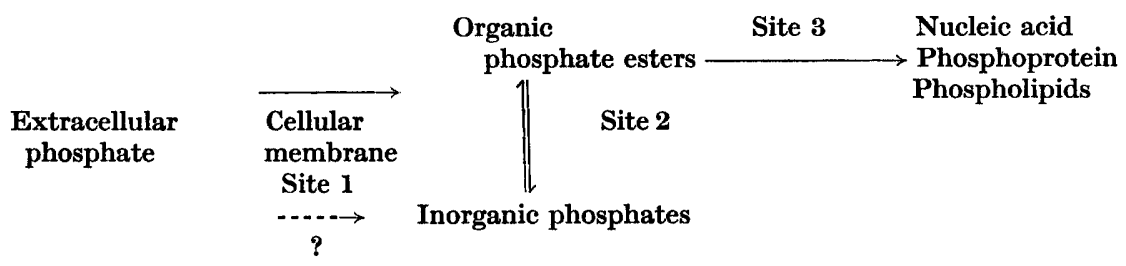

A diminution of phosphate accumulation by DNP can be pictured as a disruption of phosphate metabolism at one or more sites.

Extrapolating from the effects of DNP on phosphate metabolism in mitochondria, lowered ATP production via the oxidative phosphorylation reactions and stimulation of ATPase activity, a decrease in organic phosphate esters and TCA insoluble compounds might be expected, perhaps accompanied by an increase in inorganic phosphate. Loughman \& Russell (1957) observed inhibition of radiophosphate accumulation in young barley roots treated with DNP; upon fractionation, they observed greatest diminution in the organic phosphate esters, specifically in the nucleotides, and an increase in orthophosphate. Styrett (1958), working with Chlorella, has reported the ATP concentration within the cells to be decreased by high concentrations of DNP. 
Similarly, it was thought that stigmasterol might produce an alteration in the pattern of distribution of phosphate which could be interpreted to indicate a site of action. In context of the sterol involvement in the guinea-pig stiffness syndrome, Van Wagtendonk \& Wulzen (1951) suggested the steroid might act as a prosthetic group for the enzyme responsible for adenylic acid phosphorylation or possibly as a restraint to ATPase activity.

The pattern found in the Tetrahymena experiments shows no disturbance in the radiophosphate distribution when the animals are subjected to $1 \times 10^{-4} \mathrm{M}-\mathrm{DNP}$ and $1 \times 10^{-5} \mathrm{M}$ stigmasterol at $\mathrm{pH} 7 \cdot 0$, either singly or in combination. This pattern, too, has an interpretation in terms of the foregoing scheme; DNP acts to prevent transfer of environmental orthophosphate across the cellular membrane to the intracellular 'pool' and apparently the sterols oppose the DNP effect.

It is not possible on the basis of the lack of change in the distribution of accumulated phosphate in the presence of $2: 4$-dinitrophenol and/or the stigmasterol to distinguish, in Tetrahymena, between a direct surface or membrane phenomenon and a general involvement of energy-requiring processes. However, regardless of which mechanism proves to be correct, it is necessary to postulate the sterol and DNP act in a related system. The sterol may act in the process of phosphate accumulation at the level of the cellular membrane or may aid in supplying the energy necessary for accumulation.

Orthophosphate entry seems to many investigators to be connected with metabolic processes at the cell surface. Helder (1952) and Lundegårdh (1955) have proposed mechanisms for surface adsorption in plants. Kamen \& Spiegelman (1948), supported by Rothstein \& Dennis (1953), argue for a cell-surface esterification as the mechanism for radiophosphate permeation in yeast.

Conner (1961) suggested that phosphate entry in Tetrahymena is an active process. DNP could influence this process in one of three ways: (1) by lowering the utilization or increasing the intracellular concentration of orthophosphate; (2) interference with an active accumulation mechanism involved in phosphate entry, directly by combining with a 'carrier'; or (3) indirectly by decreasing the supply of energy required for active transport (Conway, 1955).

Further elucidation of the site and mode of DNP depression and sterol elevation of phosphate accumulation is being attempted by noting if there is sterol interaction with DNP with regard to respiratory elevation (Hamburger \& Zeuthen, 1957), respiratory quotient elevation (inhibition of the Pasteur effect) and glycogen loss. An interaction between the sterol and DNP in all of these phenomena would favour a generalized energy hypothesis or interaction in the energy supply mechanisms, while a lack of sterol influence on these DNP-induced disturbances of metabolism would favour a membrane site of action.

This work was supported in part by Bryn Mawr College, the United States Public Health Service (no. E-1065) and the United States National Science Foundation Grant no. G-7642. Two of us (R. G. and M. S. K.) were participants in the Undergraduate Research Participation Program of the National Science Foundation. 


\section{REFERENCES}

ConNer, R. L. (1957). Interaction of stigmasterol and 2:4-dinitrophenol in the growth of Tetrahymena pyriformis. Science, 126, 698.

CoNNER, R. L. (1958). Inhibition of growth of Tetrahymena pyriformis by certain steroids. J. Protozool. (Suppl. v), 19.

Conner, R. L. (1959a). The effect of stigmasterol on the uptake of phosphate in Tetrahymena pyriformis. J. Protozool. (Suppl. vi), 10.

CoNNER, R. L. $(1959 b)$. Inhibition of growth of Tetrahymena pyriformis by certain steroids. J. gen. Microbiol. 21, 180.

Conner, R. L. \& Nakatani, M. (1958). Stigmasterol antagonism of certain growth inhibitors for Tetrahymena pyriformis. Arch. Biochem. Biophys. 74, 175.

Conner, R. L., Goldberg, R. \& Kornacker, M. S. (1961). The influence of hydrogen ions and 2:4-dinitrophenol on phosphate accumulation in Tetrahymena. J. gen. Microbiol. 24, 239.

CoNway, E. J. (1955). Evidence for a redox pump with active transport of cations. Int. Rev. Cytol. 4, 377.

Hamburger, E. \& ZeUthen, E. (1957). Synchronous divisions in Tetrahymena pyriformis as studied in an inorganic medium. The effect of 2:4-dinitrophenol. Exp. Cell Res. 13, 443.

Heider, R. J. (1952). Analysis of the process of anion uptake of intact maize plants. Acta Bot. neerl. 1, 361.

HUNTER, F. E. JUN. (1951). Oxidative phosphorylation during electron transport. In Symposium on Phosphorus Metabolism, 1, 297. Ed. E. MElroy and B. Glass. Baltimore: Johns Hopkins Press.

Kamen, M. D. \& SpIEgelman, S. (1948). Studies on the phosphate metabolism of some unicellular organisms. Cold. Spr. Harb. Symp. quant. Biol. 13, 151.

Loughman, B. C. \& Russell, R. S. (1957). The absorption and utilization of phosphate by young barley plants. II. The initial stages of phosphate metabolism in roots. J. exp. Bot. 8, 272.

LETTRE, H. (1951). Über Zellteilungsgifte. Scientia, 86, 290.

Loomis, W. F. \& LipmanN, F. (1948). Reversible inhibition of the coupling between phosphorylation and oxidation. J. biol. Chem. 173, 807.

LUNDEGRRDH, H. (1955). Mechanisms of absorption, transport, accumulation and secretion of ions. Annu. Rev. Pl. Physiol. 6, 1.

Rothstein, A. \& Dennis, C. (1953). The relationship of the cell surface to metabolism. The stimulation of fermentation by extracellular potassium. Arch. Biochem. Biophys. 44, 18.

STYRETT, W. (1958). Respiration rate and internal adenosine triphosphate concentration in chlorella. Arch. Biochem. Biophys. 75, 177.

van Wagtendonk, W. J. \& Wulzen, R. (1951). Physiological and chemical aspects of the antistiffness factor essential for guinea pigs. Vitam. \& Horm. 8, 69.

WADE, R. \& JonEs, H. W. JUN. (1956a). Effect of progesterone on mitochondrial adenosinetriphosphatase. J. biol. Chem. 220, 547.

WADE, R. \& JoNES, H. W. JUN. (1956b). Effect of progesterone on oxidative phosphorylation. J. biol. Chem. 220, 553. 